\title{
URBAN PARK'S IMPACT ON OLDER MIGRANT PARENTS' WELL-BEING IN CHINA: A CASE STUDY OF SHANGHAI
}

\author{
QIAOWEI YANG ${ }^{1}, \mathrm{ANG} \mathrm{LI}^{2} \&$ LU WANG ${ }^{2}$ \\ ${ }^{1}$ School of Civil Engineering and Architecture, Zhejiang Sci-Tech University, China. \\ ${ }^{2}$ School of Architecture, Planning and Landscape, Newcastle University, United Kingdom.
}

\begin{abstract}
The emerging group of migrant older parents ("MOP", which refers to older people who leave their homes for other cities where their adult children work or reside in) in China is increasing in population, and they are making irreplaceable contribution to families as well as to our society. However, little was known about their well-being and how urban park could promote their social engagement. Therefore, this article takes the People's Park of Shanghai for a study case, trying to identify the relationship between MOP and urban park, and what their needs and related issues are. Findings show that MOP in China could promote their social engagement by participating in a variety of cultural activities, and familial obligations might influence MOP's use of park but could also provide opportunities of socialization, in particular, taking care of grandchildren. In addition, for MOP, the space of park plays a more important role in their outdoor lives than that of community. In short, urban park serves as an irreplaceable role in MOP's social engagement. But, nonetheless, in the context of today's China, the needs of older people, in particular, MOP, for sufficient and more age-friendly outdoor activity places are often ignored. Furthermore, MOP tend to be more concerned with living cost, thus, an age-friendly city list for them would also need to include low cost or even free outdoor activity places and public transport. Keywords: China, migrant older parents (MOP), social engagement, urban park, well-being.
\end{abstract}

\section{INTRODUCTION}

Ageing population has been one of the major challenges across the world. In China, this issue might become even more complex due to the country's fast ageing population as well as the process of urbanization at an unprecedented speed. It is predicted that $36.5 \%$ of Chinese will be aged 60 and over in 2050 [1], and China's urbanisation rate will reach about $75 \%$ by then [2]. A report shows that China's population would very likely be 1.35 billion in 2050 [1]. Based on these facts, it can be predicted that the ageing population of urban areas of China would be about 0.4 billion, which makes up around $29 \%$ of the country's population. Thus, in such a context, how to support older people to age well in urban built environment has been recognised as one of the most pressing issues in this country.

Literature shows that social engagement is positively associated with well-being [3], [4], because, for instance, it can reduce loneliness and can potentially act as a buffer against the adverse effects of socio-economic disadvantage for older people [5].

Based on this, in the authors' previous research (see [6]), the public park has been identified as a special urban place that can promote an emerging social activity of older Chinese, i.e. the "parents blind date", because this form of urban place has a series of unique characteristics, including the functional space and the natural scenery, which can be able to create a more age-friendly environment for older people's activities.

During the research, new finding was raised from the researcher's fieldwork: A relatively large proportion of these older people who engaged in the "parents blind date" were "migrant older parents" (hereinafter called "MOP"). In this article, the "MOP" refers to older people who leave their homes for other cities where their adult children work or reside in. 
Several socio-economic and cultural factors brought about the emergence of the MOP. First, large cities are seen as great magnets not only for capital investment, but also for well educated, entrepreneurial people who are looking forward to working hard and making a better life there [7]. Thus, sharp regional disparities drive people, especially young people, to move from their small home cities or rural areas to more developed large ones.

However, these migrant young people might be experiencing higher pressure both in life and working. A study reveals that urban temporary migrant population has to pay much more money for housing than the permanent residents mainly due to the restriction of the hukou, which is the household registration system [8]. Furthermore, these migrant young people tend to be struggling to get a balance between family and work, because as an investigation points out that organizational leaders and some workers in China accept worklife conflicts as a fact of life, and the leaders are "less sympathetic towards women's (and men's) childcare needs and are unwilling to introduce policy to accommodate family commitments" ([9], p. 18).

Thus, one of the most important factors that bring about the emergency of MOP is that these older people can reduce their adult children's pressure of life, for instance, they can look after their grandchildren [10], allowing adult children to save money or energy on these. Hence, many older people choose to move to their children's homes to support younger generations' life and work.

However, the majority of MOP might live with their children temporarily, because a baseline study discovers that only $37.8 \%$ of older people live with their children [11]. There might be a series of negative factors that push MOP to move back home. For example, Chinese older migration population tends to have limited access to social benefits, such as the basic health insurance system, due to various institutional barriers, especially the hukou system [12].

Furthermore, MOP who lack extensive social network in an unfamiliar city might be experiencing a lower degree of social engagement. In particular, the MOP are a marginalised social group in a city, and what is more the country has not carried out any action plans for supporting their quality of life [13]. In light of this, this article will continue to focus on the space of the urban park but discuss its impacts on the MOP, trying to develop an age-friendly urban park checklist for promoting the well-being of the MOP.

\section{LITERATURE REVIEW}

Migrant people in Chinese cities might be facing a series of challenges in the process of integration into an unfamiliar urban context. Currently, related research focuses on the conditions of migrant workers. For instance, it has been identified that a large number of migrant workers might be experiencing workplace bullying [14]; in addition, a study discovers that due to individual factors, such as lack of knowledge and willingness as well as macro-level factors, including type of employer and industry, rural-to-urban migrant workers tend to have low participation in welfare program, which means that they have not been socially integrated into urban communities [15].

Some studies also highlight the role of urban public space in supporting migrant people's quality of life. For example, the public space of a city not only provides a space for migrant street vendors' business, but also creates a place in which these migrant people could contact local residents, which is beneficial to their integration into the local context [16]. However, in large cities like Beijing, the migrants' right of urban space is always restricted by local authorities: they tend to become victims of the city's spatial restructuring, for instance, they have to move homes because of the transformation of their original neighbourhoods [17]. 
Studies presented above concentrate on migrant people who are more active economically, such as the migrant workers [17] and migrant street vendors [16], but lack sufficient and deep insight into migrant older people, who seem to be "less" capable of contributing to the growth of economy. In fact, active older people can be a resource in society acting as volunteers and supporting their neighbours on street committees; also, healthy older people may well be child carers, allowing other family members to be economic actors. A report issued by the ONS [18] (Office for National Statistics of the UK.) shows that in the UK, unpaid social care would cost the country $£ 57$ billion if society had to pay wages for it, and most of the work was done by older people. This calculation is not available for China; however, it does provide counter-evidence to the idea that only paid work is of economic importance to the country.

Moreover, it is argued that migrant workers' social capital is clearly related to their social engagement, but findings of another investigation indicate that the main factors that drive Chinese migrant workers to engage in social engagement might be more physically tangible evidence and reasons, for instance, economic consideration, rather than more psychological concepts like place attachment and trust [19]. Nevertheless, for older people, the impact of an increase in household income per capita on their life satisfaction is weaker than that of younger people [20], and older people's well-being might be less influenced by income than the middle aged as well [21]. In other words, the factors that drive migrant older people to participate in social activities might be quite different from younger migrant workers.

Furthermore, place attachment might not be a major driver in migrant workers' social engagement [19], and the space produced by migrant street vendors can be highly dynamic [16]. But, nonetheless, place is very important in supporting older people's daily lives, as Rowles [22] points out older people may become more and more concerned with immediate environmental context, and rely more and more upon local resources due to physiological decline, economic deprivation and traumatising effects of rapid societal change.

In an urban setting, green space has significant implications for older people's quality of life. In the age-friendly cities framework the WHO [23] (World Health Organization) points out that "[h]aving green spaces is one of the most commonly mentioned age-friendly features"([23], p. 13), and it is suggested that green spaces should be "well-maintained and safe, with adequate shelter, toilet facilities and seating that can be easily accessed" ([23], p. 18).

The WHO's framework is based on the concept of active ageing, of which participation is one of the critical facets [23],[24]. Although this age-friendly cities guide does not provide further discussion on the role of green spaces, especially the urban park, in promoting older people's social engagement, an increasing body of research has proven this.

Urban park bears the main responsibilities of public outdoor activities, and its functional spaces, natural scenery and fitness facilities are good guarantee for the outdoor activities of older people [6]. Chiesura [25] defines parks as public activity occasion, where the public could do some activities, such as visiting, sightseeing, seeking recreation, conducting scientific culture and doing physical exercise. Moreover, it is argued that an age-friendly park provides older people with opportunities to experience benefits, such as a sense of immediate pleasure and the opportunity to engage in simple, nonchallenging activities [26].

Therefore, through offering spaces for these activities, parks can support older people's social interaction [27]. For instance, urban park creates a public space in which older people's daily walking routine could happen, thereby encouraging recurring encounters between familiar strangers, which "sustains an atmosphere of fellowship that encourages people to notice, and care for, each other" ([28], p. 166). 
Nevertheless, various segments of older visitors have different park preferences, thus, park needs to offer facilities that allow for combined activities and uses, such as playgrounds for older people who look after grandchildren and benches for those who need to sit frequently [27]. Furthermore, it has also been identified that culture might have impacts on older people's preference or perspective on park use. For example, a study of park use of older Chicago dwellers from four ethnic groups shows that older people's preferences in engaging activities in parks are "consistent with both individualist and collectivist cultural orientations" ([26], p. 217). Moreover, a research conducted in Hong Kong, China, finds that cultural differences will lead to different implications for facilitating urban park use of older people in Hong Kong, which might be different from those in western societies [29]. In addition, the "parents blind date", which is a unique older people's activity that is shaped by Chinese culture, is emerging as a popular event which takes place in parks of large and medium cities in China [6].

Based on these findings of existed research, it can be identified that MOP in China might be facing three challenges in social engagement in parks. First, MOP tend to have weak social network in their immigrant cities, which apparently is a negative factor that impacts their participation in social activities. Second, MOP in Chinese big cities like Beijing and Shanghai often come from different regions of this huge country, thus, they might have diverse needs for activities or park use due to different cultures. Third, MOP often have distinct characteristics, for instance, they tend to be involved in familial obligations, such as housekeeping and taking care of grandchildren, hence, this special segment of older visitors might have their own specific park preference.

However, existing literature lacks sufficient reflection on these issues and does not provide suggestions on how to address them for MOP's social engagement in urban parks. Therefore, this article focuses on a series of related aspects such as culture, familial obligation and local social network, trying to answer the research question: How can urban park promote MOP's social engagement by addressing issues in relation to these three aspects.

\section{METHODS}

In order to explore the research question, questionnaire and semi-structured interview based on Shanghai People's Park were embraced. The People's Park, which opened in 1952, is located in the city centre of Shanghai (as shown in Fig. 1). The park covers approximately 9.8 ha, and it is near to some important public facilities and must-see city attractions and landmarks, such as the Nanjing Road (a major shopping street), the City Hall, the Bund and the Oriental Pearl Tower. Moreover, there are nearly 20 bus lines and three metro lines that connect People's Park to other parts of the city. The reasons for choosing this park were developed under three headings. The first reason was the familiarity of the case study park to the authors because this article is a continuation and upgrade from previous research. The second reason was that People's Park was located in the most prosperous place in central Shanghai which means it is able to access and interview different classes of MOP. The third reason was the presence of different social activities including both general and unique activities, such as Parents' Blind Date and English Corner which made People's Park famous in the world (see Fig. 2).

A questionnaire with 11 questions was produced and handed out among older people who were encountered in the park randomly. Apart from identifying whether participants were local permanent residents or MOP, this questionnaire focused on MOP's perception and evaluation of the park's role in their daily lives: Whether the park helped to promote MOP's social engagement and is the park more important than communities to them. The authors conducted this work in a week's time (5-11 November 2018) and twice on each day during the period (once in morning and once in the afternoon). In the park, contacted older people 
上海市行政区划图

ADMINISTRATIVE MAP OF SHANGHAI
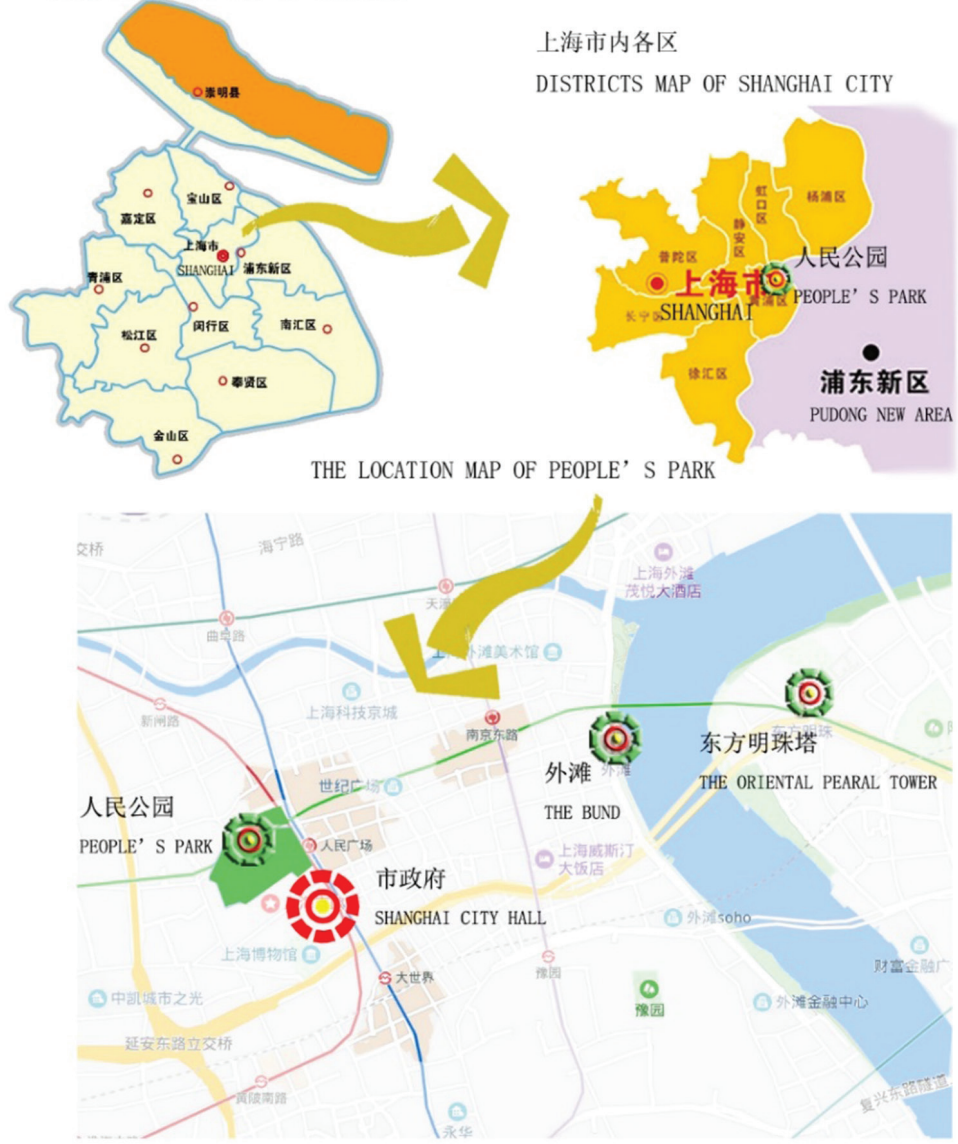

Figure 1: The location of the People's Park in Shanghai.

Source: The authors.
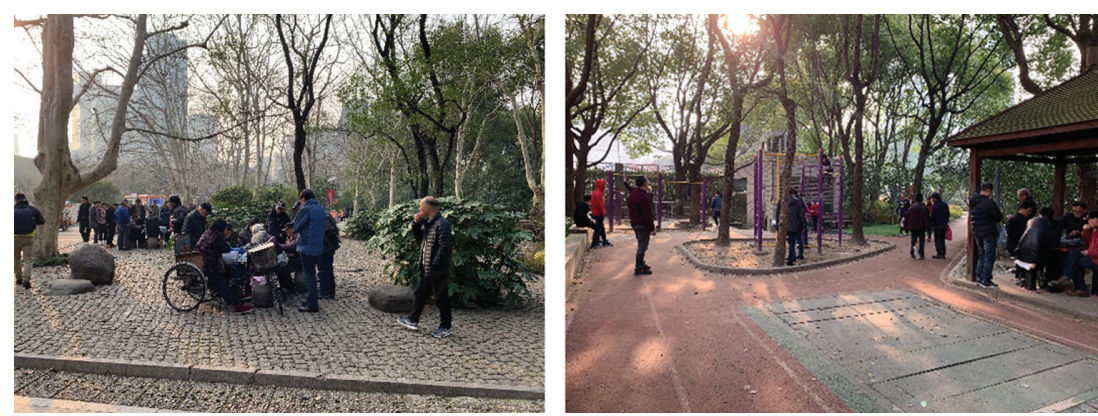

Figure 2: Older people playing cards and using outdoor gym in the People's Park.

Source: the authors. 
were first informed about the purpose of the investigation and the researchers guaranteed that all participants' privacy would be strictly protected. Then we asked if they were happy to fill in the questionnaire voluntarily and they could refuse and leave any time without any reason. In total 109 copies of questionnaire were handed out and 78 valid copies were collected $(\mathrm{n}=78)$, in which 57 participants were recognized as MOP $(\mathrm{n}=57)$.

After obtaining their agreement, 30 interviews were conducted with these participant MOP, and each with an approximate duration of 30 minutes. The interviewees were all MOP who were randomly found in three areas of People's Park: fitness area, English Corner and Parents' Blind Date area, representing the physical, cultural and social activity. The interviews were designed to be semi-structured and questions were reflected to the culture, familial obligation and local social network of MOP.

\section{FINDINGS}

4.1 Results of questionnaire: Perceptions among MOP and local older residents

In total, 78 older people, among whom 57 were recognized as MOP, in the People's Park completed and returned valid questionnaire forms. The basic information of these participants is presented in Table 1.

MOP often participate in a variety of activities in the park, which is shown in Table 2. According to the results of questionnaire, among MOP taking care of grandchildren (68.4\%) was the most frequently mentioned activity in the park, followed by making or talking to friends $(52.6 \%)$ and working out $(40.1 \%)$. 33.3\% of MOP would participate in other activities. These results reflect that taking care of grandchildren is a common familial obligation

Table 1: Basic information of participants in questionnaire.

\begin{tabular}{lccccccc}
\hline & $\begin{array}{c}\text { Participants' } \\
\text { Number }\end{array}$ & Male & Female & $\begin{array}{c}\text { Aged } \\
\mathbf{5 5}-\mathbf{6 5}\end{array}$ & $\begin{array}{c}\text { Aged } \\
\mathbf{6 6 - 7 5}\end{array}$ & $\begin{array}{c}\text { Aged } \\
\mathbf{7 6}-\mathbf{8 5}\end{array}$ & $\begin{array}{c}\text { Aged 85 } \\
\text { and over }\end{array}$ \\
\hline MOP & 57 & 25 & 32 & 23 & 27 & 7 & 0 \\
$\begin{array}{l}\text { Local } \\
\text { residents }\end{array}$ & 21 & 8 & 13 & 3 & 4 & 9 & 5 \\
Total & 78 & 33 & 45 & 26 & 31 & 15 & 5 \\
\hline
\end{tabular}

Source: The authors.

Table 2: Activities among MOP in the park.

\begin{tabular}{lcccc}
\hline & $\begin{array}{c}\text { Working } \\
\text { out }\end{array}$ & $\begin{array}{c}\text { Marking or talking } \\
\text { to friends }\end{array}$ & $\begin{array}{c}\text { Taking care of } \\
\text { grandchildren }\end{array}$ & Other activities \\
\hline $\begin{array}{l}\text { Number of MOP } \\
\text { engaged in }\end{array}$ & 23 & 30 & 39 & 19 \\
Percentage & 40.1 & 52.6 & 68.4 & 33.3 \\
\hline
\end{tabular}

Source: The authors. 
Table 3: Perceptions of park and community among MOP and local residents.

\begin{tabular}{llccc}
\hline & & $\begin{array}{c}\text { Park meets } \\
\text { needs }\end{array}$ & $\begin{array}{c}\text { Park's role in } \\
\text { social life }\end{array}$ & Park vs. community \\
\hline Born in & Pearson Correlation & .199 & -.063 & $-.540^{* *}$ \\
Shanghai? & Sig. (2-tailed) & .081 & .584 & .000 \\
& & & & -15.769 \\
& $\begin{array}{l}\text { Sum of Squares } \\
\text { and Cross-products }\end{array}$ & 4.808 & -1.615 & -.205 \\
& Covariance & .062 & -.021 & 78 \\
\hline
\end{tabular}

** Correlation is significant at the 0.01 level (2-tailed).

among MOP, which is also an important reason why MOP moved to Shanghai. But at the same time, apart from this, they could still engage in other outdoor activities in the park, such as working out and talking to friends. The result might indicate that this familial obligation does not necessarily influence MOP's other activities negatively.

In order to explore more on the role of park in MOP's well-being, the data collected in questionnaire were further processed statistically by using IBM SPSS (Statistical Package for the Social Sciences).

As shown in Table 3, the person correlation of two variables, i.e. "Boring in Shanghai?" and "Park vs. community", is $-0.540(p=-0.540)$, and this value is significant at the 0.01 level. This result indicates that MOP tend to think that park plays a more important role in supporting their social network than communities do.

In Table 4, the value of Pearson correlation of "Park meets needs" and "Park's role in social life" is $0.269(p=0.269)$, and SPSS highlights that this value for the correlation is significant

Table 4: Older people's needs and social life in park.

\begin{tabular}{llccc}
\hline & & \multicolumn{3}{c}{ Park's role } \\
& & Born in Shanghai? & $\begin{array}{c}\text { in social life } \\
\text { in Park vs. community }\end{array}$ \\
\hline $\begin{array}{l}\text { Park meets } \\
\text { needs }\end{array}$ & $\begin{array}{l}\text { Pearson } \\
\text { Correlation }\end{array}$ & .199 & $.269^{*}$ & -.220 \\
& $\begin{array}{l}\text { Sig. (2-tailed) } \\
\text { Sum of }\end{array}$ & .081 & .017 & .053 \\
& $\begin{array}{l}\text { Squares and } \\
\text { Cross-products }\end{array}$ & 4.808 & 10.897 & -10.128 \\
& & & \\
Covariance & .062 & .142 & -.132 \\
& $\mathrm{~N}$ & 78 & 78 & 78 \\
\hline
\end{tabular}

* Correlation is significant at the 0.05 level (2-tailed). 
at the 0.05 level. This result reveals that if the park could meet more needs of older people, including MOP, then the park would play a bigger role in supporting older people's social engagement. In other words, how to meet older people's diverse needs of space use is a key to promoting their social engagement in the park. Thus, MOP's needs are the key to delivering an age-friendly park for them.

\subsection{Culture: A positive factor in MOP's social engagement}

Cultural engagement has positive impacts on older people's social and cultural capitals, thereby improving their health conditions, but individual's background, such as class and socio-economic status, shapes older person's preference of activities and understanding of a certain cultural practice [30]. For MOP who come from different regions of China, they might have their own preferred cultural activities, but in city of a different cultural context, they often feel frustrated because of lacking people of the same cultural interests. Nevertheless, they can still keep cultural engagement through participating in a wider range of activities.

"When I was at home in Anhui, I used to go out and sing and watch Huang-mei Opera with my old friends quite often. But now I couldn't do that in Shanghai, because Huang-mei Opera is not popular here." (An older lady who comes from Anhui, 68)

"Sometimes there will be cultural events take place in the park, such as photographic exhibitions. "(An older gentleman who comes from Jiangsu, 65)

"I love watching and playing Chinese chess in the park, and through doing this I have made several new friends." (An older gentleman who comes from Henan, 71)

Apparently, a wider range of cultural activities can attract more number of older people to take part in, especially MOP who are of different backgrounds. In this sense, an age-friendly park should be able to provide a space that could be used to address various needs of cultural activities. For instance, many older Chinese love practising tai chi or square dancing outdoors, thus, a park will be required to offer flat and large open space for these activities. Furthermore, compared with other urban open spaces such as pedestrian street and square, park can provide relatively safe and quiet environment for older people due to its location and traffic restriction.

In addition, park can offer more facilities to facilitate older people's activities. Findings of observation show that a lot of older people play Chinese chess, sing and dance frequently in parks across Shanghai. In light of this, these parks could put more seats and tables for chess and cards, and stages for performance. Furthermore, it has been identified that existing facilities, such as seats and tables are not very suitable for older people to use. Taking park seats as example, many of them are made of stone, which is cold for older people especially in winter, and the lack of a backrest in their design creates discomfort.

\subsection{Familial obligations: Challenges but also opportunities}

Results of questionnaire and interviews show that MOP tend to be involved in familial obligations, in which children caring is the most frequently mentioned housework duty. Responses of the interviewees also indicate that this housework takes up quite a lot of time of them. Despite this, some of MOP said that the use of park could be better integrated into this familial obligation.

"Some parks have entertainment facilities for children, and I often take my grandson there. In that place I can encounter other counterparts with their grandchildren, so we get 
opportunities to talk to each other while watching children playing." (An older lady who comes from Anhui, 62)

"Both my grandson and I love going to park very much. Kids love playing together and we grandparents love talking to each other too." (An older lady from Jiangxi, 63)

Results of interviews highlight a point: Most MOP are willing to have activities in park, but sometimes they have to give up some time for completing housework. But, nonetheless, parks can provide opportunities for MOP who are involved in child caring to promote social engagement: These parks not only create a healthy environment for children, but also a place where grandparents could encounter other counterparts. Green space, for instance, parks can exert positive influence on children's growing up. Relevant research has discovered that access to green space is associated with improved mental well-being and overall health of children [31], for instance, higher residential surrounding greenness and higher proximity to green spaces are beneficial to children's respiratory health [32]. Thus, children need to visit parks frequently, for instance, they love to play on playground, as a consequence, their grandparents will watch them and could get opportunities to meet and talk to their counterparts. In addition, children caring might become a shared topic among these older people, thereby enlarging MOP's social network.

However, it has also been identified that urban planning could further optimize the location of parks to make them more easily accessible to MOP. For this group of older people, parks within their walking distance become rather important because first MOP tend to be involved in a lot of housework duties, and second some of them especially those from rural areas might be sensitive to traffic cost and less confident to use Shanghai's seemingly "complex" public transportation. Moreover, the space of park could be both age- and kids-friendly: Ramps will create a barrier-free place for both disabled older people and those who push baby carriages, but some parks of Shanghai lack these accessible facilities, especially at their entrance.

\subsection{Park or community?}

Although it is argued that older people tend to be more concerned with their immediate environment [22], and especially they tend to have strong attachment to neighbourhood [33], interviewees' response indicated that compared with community, MOP tended to have a preference for parks.

"I don't know any local residents in the community....I prefer to come here [the park] because I can often encounter other older people who come from Anhui as well....we all love to have activities in the park." (An older gentleman from Anhui)

"Of course I can use the community activity centre, but I don't go there often, because I don't have many friends in my son's community and we can only take part in a limited range of activities in the activity centre such as playing chess and cards and playing ball games...." (An older lady of 71 from Jiangxi)

Almost every community in Shanghai has an activity centre, but MOP prefer to engage in activities in parks more frequently. Compared with community space, the park has several advantages in attracting MOP. First, community centre only provides places for limited activities, and some MOP might be more interested in other activities. For instance, an older gentleman from Anhui said he loved playing mahjong, but the community activity centre did not have a place for that. Parks, however, could offer much larger space for a bigger range of activities, such as tai chi and dancing. Second, due to the lack of social network of local 
community as well as barriers of dialect and culture, MOP tend to have more difficulties in taking part in community activities. Nevertheless, parks could be able to provide more opportunities for MOP to encounter their counterparts who come from the same region and share the same culture and interests of activities. Third, many communities, in particular the old ones, do not have sufficient outdoor space, but some MOP prefer to have activities outdoors, for example, some older people said they loved playing Chinese chess outdoors because indoor air quality was not ideal especially when some people smoked. Parks provide high quality environment, and furthermore, MOP's activities, such as square dancing and singing, in parks will not influence people's lives who are living nearby, otherwise it might cause conflicts with other residents of the community.

\section{DISCUSSION}

Participation in leisure and social activities is positively associated with the QoL (quality of life) of older Chinese [34]-[36], and findings of this research further highlight that those activities would promote MOP's social engagement and improve their well-being. However, the city government does not give priority to this issue. Instead, local action plans focus on constructing a care service system; for instance, community care service stations. Clearly, the government aims to provide better services for older people. But, there is also a powerful existing financial consideration behind this policy: they expect financial benefits from providing care services by recruiting care workers, improving medical care through upgrading medical professionals and facilities, and offering more accommodation by means of building care homes.

For an ambitious mega city like Shanghai, economic growth is its first goal, which can be identified in the city's 13th Five-Year Plan (2016-2020). Therefore, compared with these economically beneficial projects, creating more activity places for older, or other less profitable age-friendly constructions, such as adding accessible facilities to old buildings and public toilets, may become less important to local government officials' agenda.

However, working to support older people's independent lives and greater health is also an economic issue, because most older people in all countries continue to be a vital resource to their families and communities [24], in particular, MOP are playing an irreplaceable role in their families: healthy older people may well be child carers, allowing other family members to be economic actors. For instance, it has been identified that older people aged over 65 years in Australia contribute nearly $\$ 39$ billion per year in unpaid caring and voluntary work [37]. This calculation is not available for China; however, it does provide counter-evidence to the idea that only paid work is of economic importance to the country.

Nevertheless, older people tend to "feel largely excluded from the ambitious plans produced by cities competing in the global marketplace" ([38], p. 601). What is worse, older people's rights to the city and to age well in their places are being eroded as they are forced to give way to the development of the city. Neither national nor local policies and documents provide clear guidelines on how to create more activity outdoor spaces in old neighbourhoods, where older people made up the majority of local population, but in the meantime, developing Chinese cities are "in a perpetual churn of demolition and new build," resulting in old neighbourhoods' decay ([39], p. 432).

In the authors' previous study on age-friendly cities, results of interviews with urban planners shows that Chinese planners are paying increasing attention to the concept of the "Neighbourhood Centre," arguing that this concept could solve issues of older people's outdoor activities. Some pilot projects of "Neighbourhood Centre" have been implemented in Suzhou, Beijing and Shanghai. 
The model of the "Neighbourhood Centre" (Chinese: lin li zhong xin (邻里中心)) has been well developed in Singapore, and essentially it is a commercial centre that provides a wide range of services for local residents from nearby neighbourhoods, including shopping, catering, entertainment and a clinic.

In Singapore, these facilities are guided and inspected by government, and commercial developers need to co-operate with government. However, neighbourhood centres in China would be funded and constructed by the developer. Although the planning authority has inspected the basic spatial construction content of the project, such as the green space, construction area and car park, it is difficult to obtain more details about what facilities and services are to be provided in this neighbourhood centre and whether the government will set out requirements for facilities and services for older people.

What is more important, for most MOP who are sensitive to living cost, would be unlikely to spend more money on engaging in outdoor or social activities. But, in essence, the neighbourhood centre is a commercial centre; in other words, the services provided may need to deliver a profit. Therefore, facilities will not be free or even low cost. Currently, one of the biggest concerns of older people is the lack of activity space, and furthermore, the majority of them want to use activity places free of charge or at low cost, as they do to attend the U3A (University of the Third Age) or play mahjong at the chess and cards rooms.

\section{CONCLUSION}

MOP is a special emerging group in China, but there is no sufficient exploration of older people of this group both in planning's research and practice. This article originally investigated the relationship between MOP's well-being and urban park, trying to identify what MOP's needs for outdoor activities are and how urban park could address these. The results show that MOP in China could promote their social engagement by participating in a variety of cultural activities, and familial obligations might influence MOP's use of park but could also provide opportunities of socialization, in particular, taking care of grandchildren. In addition, for MOP, the space of park plays a more important role in their outdoor lives than that of community. In short, urban park serves as an irreplaceable role in MOP's social engagement.

But, nonetheless, in the context of today's China, the needs of older people, in particular, MOP, for sufficient and more age-friendly outdoor activity places are often ignored. Instead, the city government tends to give priority to more profitable projects, such as developing the care service industry. Older people's rights to age well in place are being forced to give way to the city's economic development. Furthermore, compared with counterparts who are local residents, MOP in mega cities like Shanghai might be more concerned with living cost, thus, an age-friendly city list for them would also include low cost or even free outdoor activity places and public transport.

Drawing upon these points discussed above, a Chinese version of checklist of age-friendly urban parks for MOP is presented as follows:

Chinese version of age-friendly urban parks for MOP

1. Parks should be easily accessible to both older people and young kids.

2. Parks should provide playground for kids, and at the same time, designers need to integrate resting area into these places for older people.

3. The cost of public transport should be low, and government need to provide specific traffic allowance to MOP with financial difficulties.

4. More and diverse cultural facilities should be set up in parks. 
5. Community park or activity centre need to pay more attention to MOP's needs and activity preference.

6. Government should pay more attention to MOP's needs and issues, and an effective channel needs to be built up for MOP's voices.

7. Policy makers need to encourage developer of Neighbourhood Centre to offer low cost or even free activity places for older people.

\section{REFERENCES}

[1] UNDESA, World Population Prospects: The 2015 Revision, New York, NY: United Nations, 2015.

[2] Liu, Y., Development course, difficulties and trends of Chinese urbanization. Research on Economics and Management, (3), pp. 20-26, 2011.

[3] Vozikaki, M., Linardakis, M., Micheli, K. \& Philalithis, A., Activity participation and well-being among European adults aged 65 years and older. Social Indicators Research, 131(2), pp. 769-795, 2017. https://doi.org/10.1007/s11205-016-1256-y

[4] Luo, Y. \& Waite, L.J., Mistreatment and psychological well-being among older adults: exploring the role of psychosocial resources and deficits. Journal of Gerontology: Social Sciences, 66B(2), pp. 217-229, 2011. https://doi.org/10.1093/geronb/gbq096

[5] Niedzwiedz, C.L., Richardson, E.A., Tunstall, H., Shortt, N.K., Mitchell, R.J. \& Pearce, J.R., The relationship between wealth and loneliness among older people across Europe: Is social participation protective? Preventive Medicine, 91, pp. 24-31, 2016. https://doi.org/10.1016/j.ypmed.2016.07.016

[6] Li, A. \& Yang, Q., Urban park and aging people in China: A new challenge from old people's 'parents blind date'. Urban Growth and the Circular Economy, 179, WIT Press, ISSN 1743-3509, 2018. https://doi.org/10.2495/ug180121

[7] Wang, Z., Paradox of controlling population scale of mage-cities. China Development, 14(2), pp. 21-24, 2014.

[8] Jiang, L., Living conditions of the floating population in urban China. Housing Studies, 21(5), pp. 719-744, 2006. https://doi.org/10.1080/02673030600807431

[9] Xiao, Y. \& Cooke, F.L., Work-life balance in China? Social policy, employer strategy and individual coping mechanism. Asia Pacific Journal of Human Resources, 50(1), pp. 6-22, 2012. https://doi.org/10.1111/j.1744-7941.2011.00005.x

[10] Chen, F., Short, S.E. \& Entwisle, B., The impact of grandparental proximity on maternal childcare in China. Population Research and Policy Review, 19(6), pp. 571-590, 2000.

[11] CHARLS Research Team, Challenges of Population Aging in China, Beijing: National School of Development, Peking University, China, 2013.

[12] Wang, Q., Health of the elderly migration population in China: Benefit from individual and local socioeconomic status? International Journal of Environmental Research and Public Health, 14(4), p. 370, 2017. https://doi.org/10.3390/ijerph14040370

[13] Li, S., A study of issues related to migrant older people in the process of urbanization. Journal of Jinan University, 20(6), pp. 71-74, 2010.

[14] Cheo, R., Migrant workers and workplace bullying in urban China. Social Indicators Research, 132(1), pp. 87-115, 2017. https://doi.org/10.1007/s11205-015-1214-0

[15] Xu, Q., Guan, X. \& Yao, F., Welfare program participation among rural-to-urban migrant workers in China. International Journal of Social Welfare, 20(1), pp. 10-21, 2011. https://doi.org/10.1111/j.1468-2397.2009.00713.x

[16] Flock, R. \& Breitung, W., Migrant street vendors in urban China and the social production of public space. Population, Space and Place, 22(2), pp. 158-169, 2016. 
[17] Jeong, J.H., From illegal migrant settlements to central business and residential districts: Restructuring of urban space in Beijing's migrant enclaves. Habitat International, 35(3), pp. 508-513, 2011. https://doi.org/10.1016/j.habitatint.2011.02.003

[18] Office for National Statistics (ONS), Unpaid carers provide social care worth $£$ 57 billion, available at https://www.ons.gov.uk/peoplepopulationandcommunity/ healthandsocialcare/healthandlifeexpectancies/articles/unpaidcarersprovidesocialcareworth57billion/2017-07-10, 2017. (accessed 10 November 2018).

[19] Palmer, N.A., Perkins, D.D. \& Xu, Q., Social capital and community participation among migrant workers in China. Journal of Community Psychology, 39(1), pp. 89-105, 2011. https://doi.org/10.1002/jcop.20419

[20] Gerlach, K. \& Stephan, G., A paper on unhappiness and unemployment in Germany. Economic Letters, 52(3), pp. 325-330,1996. https://doi.org/10.1016/s0165-1765 (96)00858-0

[21] Cummins, R.A., Eckersley, R., Kai, L.S., Okerstrom, E., Davern, M. \& Woener, J., Australian Unity Well-being Index Survey 11, Report 11.0, The Well-being of Australians - Personal Financial Debt, Australian Centre on Quality of Life, 2004.

[22] Rowles, G., Prisoners of Space? Exploring the Geographical Experience of Older People, Boulder: Westview Press, 1978.

[23] WHO., Global Age-friendly Cities: A Guide, Geneva: World Health Organization, 2007.

[24] WHO., Active ageing: a policy framework. The Aging Male, 5(1), pp. 1-37, 2002.

[25] Chiesura, A., The role of urban parks for the sustainable city. Landscape and Urban Planning, 68(1), pp. 129-138, 2004. https://doi.org/10.1016/j.landurbplan.2003.08.003

[26] Tinsley, H.E., Tinsley, D.J. \& Croskeys, C.E., Park usage, social milieu, and psychosocial benefits of park use reported by older urban park users from four ethnic groups. Leisure Sciences, 24(2), pp. 199-218, 2002. https://doi.org/10.1080/01490400252900158

[27] Kemperman, A.D. \& Timmermans, H.J., Heterogeneity in urban park use of aging visitors: A latent class analysis. Leisure Sciences, 28(1), pp. 57-71, 2006. https://doi. org/10.1080/01490400500332710

[28] Eck, D. \& Pijpers, R., Encounters in place ballet: a phenomenological perspective on older people's walking routines in an urban park. Area, 49(2), pp. 166-173, 2017. https://doi.org/10.1111/area.12311

[29] Hung, K. \& Crompton, J.L., Benefits and constraints associated with the use of an urban park reported by a sample of elderly in Hong Kong. Leisure Studies, 25(3), pp. 291-311, 2006. https://doi.org/10.1080/02614360500409810

[30] Goulding, A., How can contemporary art contribute toward the development of social and cultural capital for people aged 64 and older. The Gerontologist, 53(6), pp. 1009-1019, 2013. https://doi.org/10.1093/geront/gns144

[31] McCormick, R., Does access to green space impact the mental well-being of children: a systematic review. Journal of Pediatric Nursing, 37, pp. 3-7, 2017. https://doi. org/10.1016/j.pedn.2017.08.027

[32] Tischer, C., Gascon, M., Fernández-Somoano, A., Tardón, A., Materola, A.L., Ibarluzea, J. \& Fuertes, E., Urban green and grey space in relation to respiratory health in children. European Respiratory Journal, 49(6), p. 1502112, 2017. https://doi. org/10.1183/13993003.02112-2015

[33] Scharf, T., Phillipson, C. \& Smith, A., Older people's perceptions of the neighbourhood: Evidence from socially deprived urban areas. Sociological Research Online, 8(4), pp. 1-12, 2003. https://doi.org/10.5153/sro.867 
[34] Chen, Y., Hicks, A. \& While, A.E., Validity and reliability of the modified Chinese version of the Older People's Quality of Life Questionnaire (OPQOL) in older people living alone in China. International Journal of Older People Nursing, 9(4), pp. 306-316, 2014. https://doi.org/10.1111/opn.12042

[35] Li, L.W., Zhang, Z., Xu, H. \& Liu, J., Leisure activities participation and depressive symptoms of older adults in urban China. The Gerontologist, 56(Suppl3), p. 199, 2016. https://doi.org/10.1093/geront/gnw162.780

[36] Chen, J., The Pedestrian Street has Been Accessible by Non-Motorized Vehicles, 2016. available at http://www.aqnews.com.cn/html/aqxw/msxw/201608/2307351.html (accessed 3 November 2018).

[37] Vaus, D., Gray, M. \& Stanton, D., Measuring the Value Of Unpaid Household, Caring and Voluntary Work of Older Australians, Melbourne: Australian Institute of Family Studies, 2003.

[38] Buffel, T., Phillipson, C. \& Scharf, T., Ageing in urban environments: Developing "age-friendly" cities. Critical Social Policy, 32(4), pp. 597-617, 2012. https://doi. org/10.1177/0261018311430457

[39] Gilroy, R., Changing landscapes of support in the lives of Chinese urban elders: voices from Wuhan neighbourhoods. Environment and Planning C: Government and Policy, 31(3), pp. 428-443, 2013. https://doi.org/10.1068/c1193 